\section{idanoturn}

Jurnal Kajian Manajemen Dakwah
Volume 3, Nomor 3, Oktober 2021

P-ISSN: 2654-4709

E-ISSN: 2654-4938

DOI: 10.24014 /idarotuna.v3i3.16339

\title{
Syariah Hotel Solo: Rekrutmen dan Seleksi Karyawan Berbasis Manajemen Syariah
}

\author{
Totok Sudaryanto ${ }^{1}$, Ade Yuliar ${ }^{2}$, Agus Wahyu Triatmo ${ }^{3}$ \\ ${ }^{1,2,3}$ Universitas Islam Negeri Raden Mas Said Surakarta \\ Email: adeyuliar2107@gmail.com
}

\begin{abstract}
The concept of Islamic hospitality has great potential in the industrial world. At the same time, this has given rise to new investments based on sharia principles in various countries. Recently, many industrial sectors carry the concept of sharia, such as halal tourism and sharia hotels. This paper discusses the Sharia Hotel in Solo, primarily examining the implementation of sharia management in the recruitment and selection process for new employees. This is important to be seen as part of the concept of Islamic hospitality. By conducting interviews, observations, and documentation, this paper shows that Syariah Hotel Solo has implemented sharia principles in the procurement of human resources through the employee recruitment and selection process. This is indicated by the existence of special criteria and special tests in recruiting and selecting employees such as being Muslim, praying, having the ability to read the Koran, the pillars of Islam, and other Islamic knowledge.
\end{abstract}

Keywords: Sharia Hotels, Recruitment, and Selection

Abstrak: Konsep keramahan Islam (Islamic Hospitality) menjadi potensi besar dalam dunia industri. Pada saat yang sama, hal ini memunculkan investasi baru yang berdasarkan prinsip-prinsip syariah di berbagai negara. Belakangan ini banyak sektor-sektor industri yang mengusung konsep syariah seperti wisata halal dan hotel-hotel syariah. Tulisan ini membahas Syariah Hotel di Solo, utamanya mengkaji tentang implementasi manajemen syariah dalam proses rekrutmen dan seleksi karyawan baru. Hal ini penting dilihat sebagai bagian dari konsep keramahan Islam. Dengan melakukan wawancara, observasi, dan dokumentasi, tulisan ini menunjukkan bahwa Syariah Hotel Solo telah melakukan prinsip-prinsip syariah dalam pengadaan sumber daya manusia melalui proses rekrutmen dan seleksi karyawan. Ini ditunjukkan dengan adanya kriteria khusus dan tes khusus dalam merekrut dan menyeleksi karyawan seperti beragama Islam, melaksanakan sholat, mempunyai kemampuan membaca Al-Quran, rukun Islam, dan pengetahuan-pengetahuan Islam lainnya.

Kata kunci: Hotel Syariah, Rekrutmen, dan Seleksi

\section{Pendahuluan}

Keramahan Islam atau Islamic hospitality sebagai potensi besar dalam industri. Hal ini diungkapkan the Economist dalam Serhan \& Alobaitha (2013) bahwa melalui keramahan Islam di Timur Tengah dan Asia menarik banyak perhatian antara perusahaan perhotelan, dan dapat membawa investasi yang didasarkan pada prinsip syariah dari berbagai belahan dunia. Bidang terkait industri pariwisata Islam diproyeksikan untuk menikmati peluang bisnis yang sangat baik (Zamani-Farahani \& Henderson, 2010). Oleh karena itu, layanan dalam sektor perhotelan syariah merupakan salah satu produk pariwisata baru yang berkembang pesat di industri pariwisata halal masuk ke dalam konsep keramahtamahan Islami atau Islamic hospitality (Yusoff et al., 2017). 
Hal ini yang mendorong bisnis perhotelan menjadi daya tarik sehingga perkembangan hotel yang menerapkan prinsip syariah tersebut semakin diminati oleh konsumen. Beberapa alasan seperti citra yang baik serta terkesan jauh dari hal negatif. Selain itu, konsumen merasa aman dan nyaman saat mereka menginap di hotel syariah bersama keluarga dan dapat melaksanakan ibadah dengan baik (Riasari, 2020). Untuk menghadapi persaingan yang kompetitif dalam industri perhotelan maka hotel-hotel syariah membutuhkan pengelolaan sumber daya manusia profesional yang mampu mengimplementasikan keramahtamahan Islami dalam setiap layanan.

Salah satu destinasi wisata yang ada di Provinsi Jawa Tengah yang memiliki daya tarik bagi wisatawan adalah Kota Solo atau Surakarta yang merupakan salah satu kota yang terletak di Provinsi Jawa Tengah. Kota Solo memiliki beberapa destinasi wisata yang beragam mulai wisata kebudayaan, wisata alam, wisata sejarah, wisata kuliner, hingga wisata religi. Ini yang membuat Kota Surakarta menjadi salah satu destinasi yang menarik sebagai tujuan utama para wisatawan nusantara maupun mancanegara. Selain itu, pada saat yang sama, ihwal ini medorong berkembangnya bisnis yang mendukung pariwisata halal dan religi termasuk munculnya penginapan atau hotel syariah di Solo. Salah satu hotel syariah tersebut adalah Syariah Hotel Solo yang menjalankan operasionalnya sesuai dengan prinsip-prinsip syariah yang ketat dan hrus dipenuhi. Beberapa persyaratan yang harus dipenuhi terutama prinsip-prinsip syariah terkait kaidah halalan thoyiban. Kaidah ini meliputi operasional, pengelolaan dan pelayanan. Operasional hotel syariah harus memenuhi prinsip syariah seperti pakainan Muslim yang menutup aurat untuk petugas hotel, seleksi tamu hotel yang berpasangan, dan pelarangan membawa minuman-minuman beralkohol (Ahmat.dkk, 2013). Unsur terpenting dalam pengembangan perhotelan syariah adalah sumber daya manusia (SDM). Di mana setiap karyawan harus memiliki karakter sesuai dengan prinsip-prinsip organisasi perusahaan. Maka karyawan perhotelan syariah membutuhkan pengelolaan dengan konsep manajemen syariah, mulai dari proses perencanaan, pengorganisasian, memimpin, mengendalikan upaya organisasi, dan menggunakan semua sumber daya organisasi lainnya berdasarkan Al-Quran dan Hadis untuk mendapat ridho Allah SWT dengan membentuk sifat Rasulullah SAW yang terdiri dari siddiq, amanah, fathonah dan tabligh (Agustin, 2018).

Salah satu hotel yang menerapkan nilai-nilai syariah dalam manajemennya di Jawa Tengah adalah Syariah Hotel Solo. Hotel ini merupakan hotel berbintang (hilal) empat dan merupakan hotel syariah terbesar di Indonesia (Swa.co.id, 2014). Aspek layanan di Syariah Hotel Solo selalu berprinsip pada nilai-nilai syariah. Tujuannya agar customer merasakan perbedaan dalam setiap layanan. Adapun hal ini sesuai dengan ketentuan peraturan yang diterbitkan oleh Kementerian Pariwisata dan Ekonomi Kreatif. Peraturan ini mencakup beberapa aspek dalam penyelenggaraan usaha hotel syariah, di antaranya adalah penggolongan usaha hotel, penilaian dalam rangka sertifikasi usaha hotel syariah, pelaksanaan sertifikasi usaha hotel syariah, dan pembinaan serta pengawasan (Peraturan Mentri Pariwisata Dan Ekonomi Kreatif Republik Indonesia Nomor 2 Tahun 2014 Tentang Pedoman Penyelenggaraan Usaha Hotel Syariah, 2014).

Syariah Hotel Solo merupakan bisnis yang menyediakan jasa pelayanan yang khas dengan branding syariah maka dalam perekrutan karyawannya dilakukan secara selektif agar sesuai 
dengan impelementasi manajemen syariah. Sistem perekrutan dan seleksi di Syariah Hotel Solo tidak hanya menghasilkan pegawai dengan status sebagai pegawai tetap saja, namun untuk meningkatkan efiktifitas perusahaan, maka Syariah Hotel Solo juga menggunakan tahapantahapan tenaga kerja berdasarkan status karyawan. Tahapan dimulai dari karyawan training, daily worker dan sampai pada tahap akhir yaitu menjadi pegawai tetap Syariah Hotel Solo.

Tabel 1. Jumlah karyawan Syariah Hotel Solo

\begin{tabular}{ccc}
\hline Tahun & $\begin{array}{c}\text { Jumlah Karyawan } \\
\text { Tetap }\end{array}$ & $\begin{array}{c}\text { Jumlah Daily Worker } \\
\text { dan Training }\end{array}$ \\
\hline 2018 & 82 & 60 \\
2019 & 82 & 60 \\
2020 & 46 & 40 \\
\hline
\end{tabular}

Sumber : HRD Syariah Hotel Solo, 2020

Kebijakan rekrutmen dan seleksi karyawan Syariah Hotel Solo berada di bagian Human Resource Departement (HRD) di mana setiap kebijakan mempertimbangkan dalam penyesuaian kebutuhan dan anggaran perusahaan. Pada tahun 2020 terjadi pengurangan karyawan cukup signifikan dikarenakan pendemi Covid-19. Pengurangan karyawan terjadi mulai awal Maret hingga saat ini, adapun penyebab penurunan jumlah karyawan di Syariah Hotel Solo dikarenakan terjadi pandemi Covid-19 yang menyebabkan kunjungan tamu mengalami penurunan yang sangat drastis (Sudaryatno \& Yudiantoro, 2021).

Tulisan ini berkontribusi pada kajian-kajian mengenai pengelolaan sumber daya manusia di hotel syariah. Kajian-kajian sebelumnya yang membahas tentang pengelolaan sumber daya manusia di hotel syariah dapat dilihat dalam penelitian Fikri (2016). Dalam penelitiannya, Fikri mengkaji tentang pelaksanaan sistem rekrutmen dan seleksi karyawan baru di hotel syariah. Temuan pentingnya menunjukkan bahwa dalam proses rekrutmen, aspek yang perlu dilihat adalah karakteristik nilai-nilai Islam yang dimiliki calon pelamar (Fikri, 2016). Temuan Fikri, dikuatkan oleh penelitian selanjutnya yang dilakukan oleh Susanti, Abdullah, \& Nurjannah (2019). Susanti, Abdullah, \& Nurjannah (2019) menjelaskan bahwa proses rekrutmen dan seleksi karyawan harus memenuhi kriteria yang telah ditentukan dengan memperhatikan kualifikasi pendidikan, pengalaman kerja, kondisi fisik serta kepribadian. Hal terpenting dalam rekrutmen dan seleksi adalah dengan memperhatikan kepercayaan dan kejujuran sesuai dengan perspektif ekonomi syariah, sehingga membantu sektor perhotelan syariah dapat tumbuh (Sucipto, 2020).

Menguatkan penelitian-penelitian sebelumnya, tulisan ini berargumen bahwa proses rekrutmen dan seleksi sumber daya manusia pada hotel syariah tidak jauh berbeda dengan hotelhotel umum lainnya. Namun, yang membedakan proses rekrutmen dan seleksi pada hotel syariah adalah tes tambahan tentang pengetahuan agama calon karyawan seperti pengetahuan tentang rukun Islam, sejarah Islam, dan pengetahuan-pengetahuan Islam lainnya. Selain tes tambahan, persyaratan khusus dalam proses rekrutmen di hotel syariah juga menjadi pembeda dengan hotelhotel umum. Pada hotel syariah menerapkan persyaratan khusus seperti beragama Islam, melaksanakan sholat lima waktu, mampu membaca Al-Qur'an, memahami Islam secara umum, 
dan lainnya. Tujuan dari tes tambahan dan persyaratan khusus ini adalah untuk mendukung konsep manajemen syariah pada Syariah Hotel Solo.

\section{Metode}

Penelitian ini menggunakan penelitian lapangan (field research) yaitu metode penelitian yang digunakan untuk memperoleh data secara langsung dari informan (Purhantara, 2010). Pendekatan yang digunakan dalam penelitian adalah pendekatan kualitatif deskriptif yaitu data yang diperoleh seperti hasil pengamatan, wawancara, analisis dokumen kemudian disusun tidak dituangkan dalam bentuk angka-angka. Penelitian ini dilakukan terhadap manajemen Syariah Hotel Solo serta Human Resources Department, sehingga dapat memperoleh gambaran yang detil mengenai implementasi manajemen syariah untuk rekrutmen dan seleksi. Tempat penelitian dilakukan di Syariah Hotel Solo yang beralamatkan di Jalan Adi Sucipto No. 47, Gonilan, Kartasura, Sukoharjo, Jawa Tengah. Sesuai dengan studi kasus yang ingin diteliti peneliti berkaitan dengan rekrutmen dan seleksi karyawan pada perusahaan.

Sumber data dalam penelitian ini diperoleh dari wawancara mendalam dengan manajemen dan HRD Syariah Hotel Solo sebagai data primer. Serta sumber data sekunder diperoleh dari buku pedoman operasional dan arsip-arsip yang terdapat di Syariah Hotel Solo. Dalam pengumpulan data peneliti melakukan wawancara, observasi atau pengamatan, dan dokumentasi. Wawancara dilakukan dengan Wisnu Yudiantoro sebagai Human Resource Manager, Sudaryatno sebagai Human Resource staff, Dwi Basuki sebagai Food and Beverage Manager, dan Erna Usniawati sebagai karyawan Housekeeping. Wawancara dilakukan di tengah Pandemi Covid-19 pada bulan September 2020 sampai dengan bulan Maret 2021. Adapun observasi dilakukan dengan cara mengikuti kegiatan rekrutmen dan seleksi yang dilakukan oleh Human Resource Department. Dokumentasi digunakan untuk melihat kegiatan rekrutmen dan seleksi dan struktur organisasi di Syariah Hotel Solo.

Penelitian ini menggunakan teknik purposive sampling. Menurut Sugiyono, purposive sampling merupakan teknik pengambilan sampel sebagai responden yang bersumber data atas pertimbangan tertentu, misalnya orang tersebut dianggap paling tahu tentang apa yang diharapkan (Sugiyono, 2015). Penggunaan purposive sampling dalam penelitian ini bertujuan untuk mengetahui bagaimana proses rekrutmen dan seleksi dengan para pihak yang mempunyai kebijakan dalam pengelolaan sumber daya manusia. Dalam upaya menjaga keabsahan data dan hasil penelitian kualitatif, maka digunakan uji validitas data dengan menggunakan model trianggulasi. Kemudian analisis data dilakukan melalui data reduction (reduksi data), data display (penyajian data) dan conclusion drawing atau verification (penarikan kesimpulan) (Sugiyono, 2015).

\section{Hasil dan Pembahasan}

\section{Sekilas Tentang Syariah Hotel Solo}

Henderson dalam Omar \& Islam (2019) menyebutkan persyaratan hotel syariah berdasarkan

pendekatan Islam antara lain: tidak ada alkohol, hanya tersedia makanan halal, Al Qur'an dan 
sajadah tersedia di setiap kamar, terdapat ruang sholat, staf yang didominasi Muslim, pakaian konservatif, pendanaan Islam, fasilitas rekreasi terpisah untuk pria dan wanita. Dalam konteks pengelolaan karyawan maka sudah seharusnya industri perhotelan syariah dalam rekrutmen dan seleksi menerapkan konsep manajemen syariah. Menurut Battour et al. bahwa literatur akademis yang berkaitan dengan atribut-atribut keagamaan ini dan fitur-fitur keagamaan di hotel syariah cenderung menjadi faktor kunci dalam proses pengambilan keputusan bagi wisatawan Muslim (Battour, et al, 2011).

Konsep manajemen syariah secara terminologi adalah manajemen yang dilandasi hukumhukum Islam yang bersumber dari Al-Quran dan Hadis. Secara khusus manajemen sumber daya manusia yang berbasis syariah lebih diarahkan pada etika perilaku yang diupayakan menjadi nilai ibadah. Penggunaan sumber daya manusia secara efektif dan bertanggung jawab merupakan suatu proses manajemen syariah untuk mencapai tujuan yang telah ditetapkan perusahaan sesuai ajaran dalam agama Islam. Singkatnya, penggunaan sumber daya manusia sebagai proses pengelolaan individu-individu dalam organisasi yang merupakan hubungan antara karyawan dengan perusahaan guna menciptakan dan memanfaatkan individu-individu atau karyawan sendiri secara produktif (Hafifuddin, 2003).

Dalam konsep sumber daya insani, proses rekrutmen adalah proses pencarian karyawan yang mampu untuk melamar sebagai karyawan. Dalam Islam, proses rekrutmen seharusnya dilakukan secara terbuka dan jujur, jauh dari aspek-aspek korupsi, kolusi dan nepotisme. Kriteria pelamar adalah yang sholeh dan layak (Fikri, 2016). Seleksi adalah upaya yang dilakukan untuk memilih dan mendapatkan tenaga kerja yang memiliki kemampuan sesuai dengan tugas-tugas yang akan dikerjakan pada jabatan yang akan ditempatinya (Zainal, 2009).

Nilai-nilai syariah yang terdapat dalam agama Islam telah meletakkan profesionalitas dalam manajemen, khususnya yang berkaitan dengan bagaimana seorang pemimpin dalam memberdayakan karyawan dalam suatu organisasi untuk mencapai kesuksesan yang optimal (Adiwarman A. Karim dalam Hastutik, 2017). Manajemen syariah di Syariah Hotel Solo telah dikelola semenjak berdirinya hotel ini dan tercantum dalam visinya menjadikan hotel syariah berbintang pertama Jawa Tengah, serta memberikan pelayanan yang berbasis syariah yang optimal sesuai dengan hotel-hotel lainny, tetapi berasaskan nilai-nilai syariah dalam agama Islam. Kemudian dalam pengelolaan karyawannya selalu diberikan kegiatan-kegiatan pendukung yang bersifat religius seperti pengajian rutin, khataman, sholat hajat, zakat dan kegiatan amal lainnya.

Manajemen syariah di Syariah Hotel Solo dikelola sebagai bisnis yang berlandaskan nilainilai syariah dengan memudahan customer untuk memenuhi kebutuhan baik dunia maupun akhirat seperti dalam hal memudahkan dalam beribadah. Dalam pemenuhan segala kebutuhan tamu dalam setiap pelayanan karyawan juga harus mampu menjalankan tugasnya, karena dalam setiap kegiatan karyawan juga mengemban amanah yang harus dipertanggung jawabkan.

Secara umum, Syariah Hotel Solo memiliki 360 kamar dan venue berkapasitas 2.000 orang. Hotel ini memiliki 12 lantai untuk kamar dimulai dari lantai 2 sampai 11, dan lantai 1 hanya berisi lobby, restoran, meetingroom, dan area kitchen, dan untuk lantai 12 berisi ballroom. 
Syariah Hotel Solo mulai diresmikan pada 11 Maret 2014 di kota Solo. Hotel ini berdiri di bawah pimpinan Hotel Anom Solo Saranatama Group (HAS) (Solo, 2021).

\section{Gambar1. Syariah Hotel Solo}

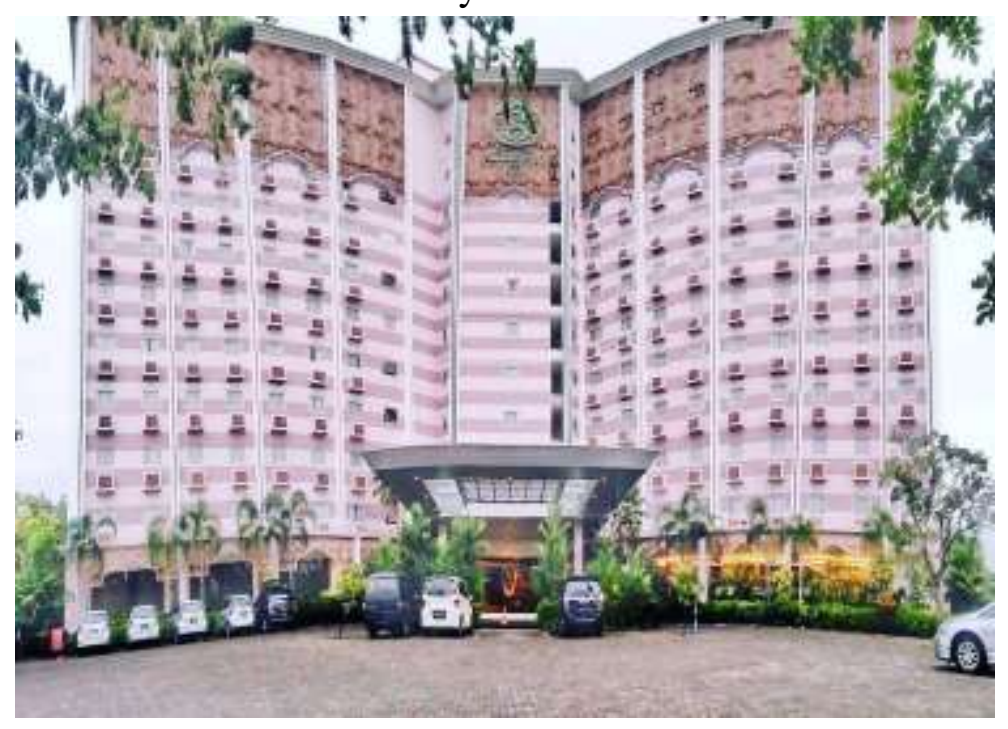

Sumber: Instagram @ syariahhotelsolo

\section{Syariah Hotel Solo: Proses Rekrutmen Karyawan}

Menurut Human Resource Department (HRD) Syariah Hotel Solo, prosedur rekrutmen karyawan dimulai dari prosedur permintaan karyawan dari divisi, kemudian proses rekrutmen, penentuan pihak yang bertanggung jawab dalam rekrutmen, dan juga waktu pelaksanaaan proses tersebut. Metode rekrutmen yang diterapkan di Syariah Hotel Solo dilakukan dengan metode tertutup maupun terbuka, tergantung dengan kebutuhan yang diperlukan dari hotel (Sudaryatno \& Basuki, 2021).

Syariah Hotel Solo dalam prosedur rekrutmen dimulai dari prosedur permintaan karyawan berdasarkan kebutuhan sumber daya manusia dari divisi-divisi. Kemudian proses rekrutmen, pihak yang bertanggung jawab dalam proses rekrutmen, dan juga waktu pelaksanaan akan diatur oleh Human Resource Department. Dalam melakukan rekrutmen Syariah Hotel Solo selalu melihat skill dan kualitas karyawan yang akan direkrut (Sudaryatno \& Yudiantoro, 2021)

Bagan 1. Proses Rekrutmen Karyawan Syariah Hotel Solo

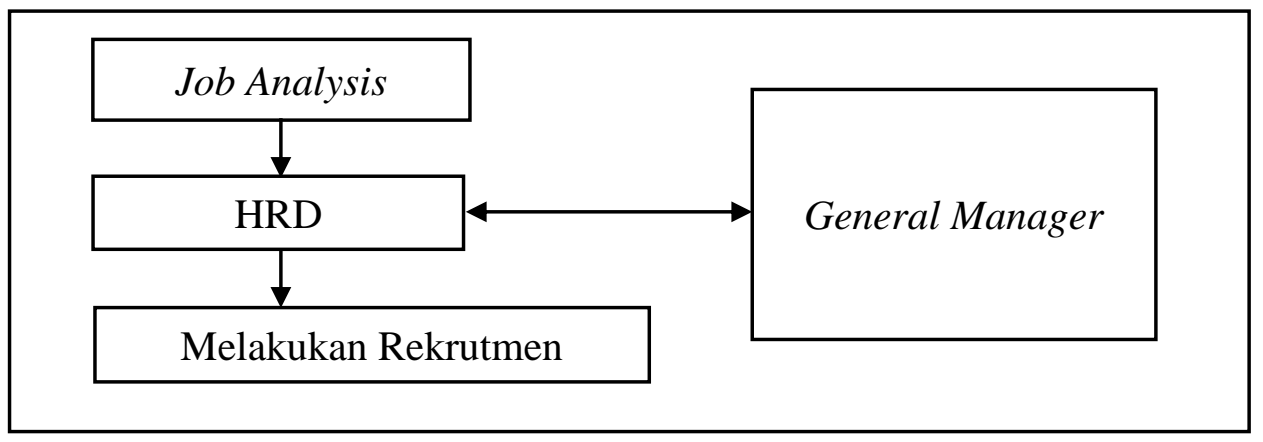

Sumber: HRD Syariah Hotel Solo, 2021 
Berdasarkan bagan di atas dapat dijelaskan sebagai berikut: Pertama, pengusulan karyawan baru dari seluruh divisi. Untuk jabatan yang mengusulkan permintaan tenaga kerja minimal menjabat sebagai supervisor. Selanjutnya dalam pengusulan formasi yang dibutuhkan harus termuat informasi yang penting terkait deskripsi seperti nama divisi atau departemen yang membutuhkan, jabatan, jumlah, persyaratan umum (umur, jenis kelamin, pendidikan formal \& non-formal, dan pengalaman kerja), persyaratan khusus, status karyawan tetap, dan jika status karyawan kontrak perlu menginfokan lama waktu yang dibutuhkan untuk mengisi kekosongan.

Kedua, setelah pihak Human Resource Department menerima usulan, maka akan ada pengecekan berdasarkan prioritas kebutuhan karyawan baru di Syariah Hotel Solo. Selanjutnya Human Resource Department akan meeting (rapat terbatas terkait pemilihan kandidat calon karyawan) dengan General Manager (GM) untuk rekrutmen karyawan posisi supervisor ke atas. Jika karyawan posisi supervisor ke bawah atau pelaksana maka membutuhkan persetujuan Human Resource Department diikuti pemberitahuan kepada General Manager. Ketiga, apabila proses kelayakan pengusulan diterima, maka Human Resource Department akan menginformasikan posisi yang kosong ke pihak internal, yaitu melalui promosi jenjang karir atau career path dan pihak eksternal yaitu sekolah-sekolah kejuruan, universitas atau ataupun media sosial yang dimiliki Syariah Hotel Solo sampai batas waktu yang sudah ditentukan.

Secara umum, tahap-tahap yang dilakukan oleh Syariah Hotel Solo dimulai dari mengidentifikasi dari kebutuhan divisi yang membutuhkan sumber daya manusia, lalu melakukan analisa jabatan berupa penentuan kriteria karyawan, dan terakir bagaimana menentukan sumber dan metode rekrutmen. Dalam hal ini, Head of Department (HoD) akan dibantu Human Resource Department dalam melakukan proses selanjutnya yaitu proses pencarian karyawan baru yang dibutuhkan. Dengan melihat dinamika dari beberapa hal tersebut dan mencocokkannya dengan perencanaan sumber daya manusia yang sudah tersusun maka akan diketahui apa yang dibutuhkan hotel. Pemenuhan kebutuhan jumlah karyawan harus disesuaikan dengan divisi yang membutuhkan sumber daya manusia berikut dengan anggaran pengeluaran karyawan. Berdasarkan wawancara dengan bapak Sudaryatno dan Yudiantoro selaku Human Resource Department, beliau menjelaskan bahwa:

"Untuk budgeting sumber daya manusia dari tahun ke tahun anggaran karyawan di Syariah Hotel Solo hanya dibolehkan sebanyak 82 karyawan. Kalau di tahun ini di bulan Maret sampai sekarang hanya terisi 46 karyawan, nanti di tahun 2021 jika kondisi sudah normal maka kembali lagi di posisi 82 karyawan (Sudaryatno \& Yudiantoro, 2020)."

Sesuai dengan penganggaran tiap-tiap departemen juga haruslah disesuaikan, agar sesuai dengan apa kebutuhan, seperti pendapat bapak Basuki selaku Food \& Beverage Manager, beliau juga menjelaskan bahwa:

"Untuk rekrutmen kita ada kuota, jadi kita di berikan kuota oleh perusahaan yang mana kita tidak boleh melebihi anggaran karyawan yang di tentukan. Jadi mengikuti kebijakan untuk tidak boleh over ataupun kekurangan, karena jika terjadi kekurangan akan mempengaruhi 
operasional (Basuki, 2021).”

Selanjutnya Syariah Hotel Solo akan menginformasikan terkait syarat umum dan khusus, agar di kemudian hari karyawan dapat mempertanggungjawabkan tugas dan amanah yang diberikan. Adapun proses pemanggilan karyawan untuk mengikuti tahap-tahap dalam rekrutmen dilakukan oleh pihak Human Resource Department. Namun, sebelum melakukan pemanggilan pelamar, Human Resource Department terlebih dahulu akan menyeleksi surat lamaran apakah sudah memenuhi dengan kualifikasi yang dibutuhkan dari masing-masing divisi. Selanjutnya melakukan wawancara tidak terstruktur, wawancara ini dilakukan oleh dua pihak yang pertama oleh Human Resource Department dan yang kedua oleh Head of Department.

\section{Syariah Hotel Solo: Proses Seleksi Karyawan}

Pada proses seleksi karyawan, calon karyawan yang telah sesuai dengan persyaratan dan kriteria-kriteria yang telah ditentukan akan dihubungi melalui e-mail maupun telepon, untuk menentukan jadwal proses awal seleksi yaitu wawancara.

Bagan 2. Proses Seleksi Karyawan Syariah Hotel Solo

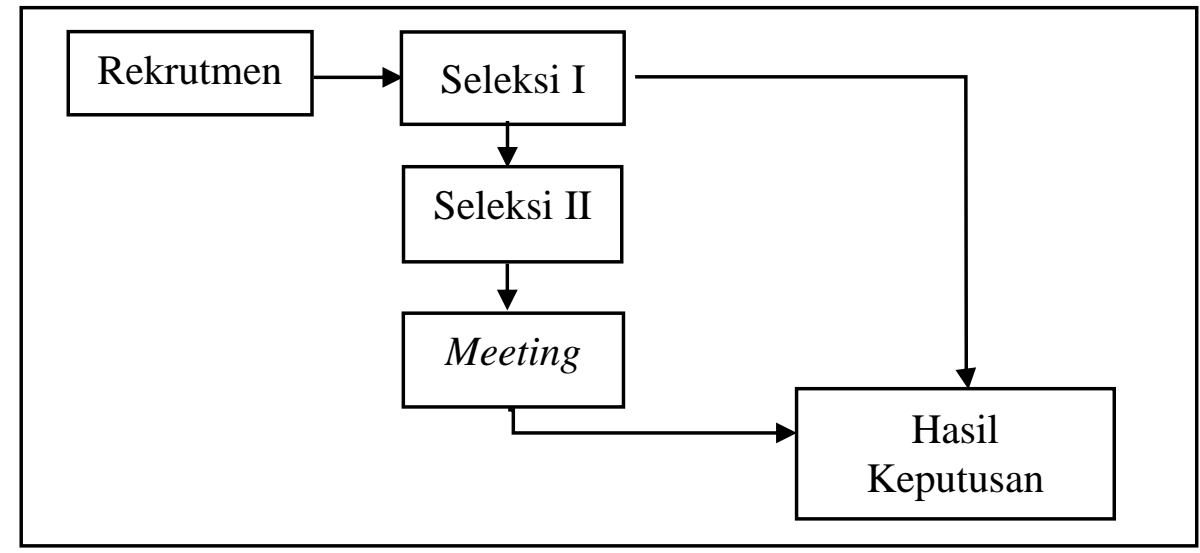

Sumber: HRD Syariah Hotel Solo, 2021

Para pelamar yang telah memenuhi spesifikasi persyaratan, maka Human Resource Department akan mengundang secara formal melalui e-mail atau telepon perihal waktu untuk wawancara. Seleksi tahap pertama, pelamar akan diinterview terkait minat dan alasan melamar pekerjaan di Syariah Hotel Solo, setelah itu diberikan form untuk diisi yang menyangkut data diri seperti nama dan alamat lengkap, jenis kelamin, riwayat pendidikan formal, kursus atau training, data profil serta susunan keluarga, hingga riwayat pekerjaan sebelumnya. Setelah selesai, pelamar kembali menghadap untuk interview tahap selanjutnya dengan Human Resource Department.

Seleksi tahap kedua, pelamar akan diwawancarai terkait latar belakang atau riwayat hidup, pengalaman kerja sebelumnya, minat melamar di Syariah Hotel Solo, sikap serta akhlak dalam beragama seperti menanyakan apakah mengerti serta memahami bacaan surat pendek dalam AlQur'an seperti surat Al-Fatihah dan bagaimana pandangan seseorang pelamar dalam beribadah 
serta pengamatan penampilan dan kebersihan juga diperhatikan. Selanjutnya, Human Resource Department akan menginformasikan apakah para kandidat pelamar dapat lulus mengikuti proses seleksi selanjutnya atau berhenti diwawancara tahap kedua.

Para pelamar yang dinyatakan lulus, selanjutnya akan mengikuti proses interview dengan Human Resource Department sesuai formasi yang diisi untuk posisi pelaksana, dan interview dengan General Manager untuk posisi supervisor ke atas. Saat interview lanjutan, dilakukan dengan Head of Department ataupun General Manager, proses interview akan dititikberatkan kepada berbagai aspek teknis dan non teknis seperti pengetahuan dan ketrampilan, hingga pengambilan keputusan hasil interview. Tidak menutup kemungkinan (untuk departemen tertentu) dapat dilakukan tes tertulis tambahan terkait skill atau kemampuan dalam bekerja. Setelah semua proses interview tersebut diatas selesai dilaksanakan, selanjutnya Head of Department yang terlibat dan dipimpin oleh Human Resource Department melaksanakan meeting untuk pengambilan keputusan dalam seleksi.

Setelah meeting memutuskan kandidat yang layak untuk ditindaklanjuti, maka Human Resource Department akan kembali menginformasikan hasil keputusan terkait seleksi karyawan yang di mana sebelum diangkat menjadi karyawan terlebih dahulu harus magang (on the job training) selama tiga bulan untuk masa uji coba. Setelah selesai maka Human Resource Department akan menggali lagi informasi kepada Head of Department atau teman sejawat untuk menimbang layak tidaknya untuk diangkat menjadi staf.

Selanjutnya Human Resource Department akan mengundang kembali calon karyawan untuk datang dan bertemu guna menerima hasil keputusan apakah diterima menjadi staf karyawan atau tidak. Jika semua selesai baru Human Resource Department membuat kesepakatan apakah menyepakati gaji (kompensasi dan benefit) untuk selanjutnya menandatangani Memorandum of Understading (MoU).

\section{Manajemen Syariah: Rekrutmen dan Seleksi Karyawan}

Dalam melakukan rekrutmen Syariah Hotel Solo melihat skill dan kualitas karyawan yang akan direkrut haruslah sesuai dengan kebutuhan perusahaan. Selanjutnya dalam teknik penilaian awal terhadap kandidat pelamar yang sesuai dengan kebutuhan yaitu berupa syarat umum administrasi yang harus dipenuhi, dengan melampirkan berkas persyaratan administrasi antara lain: surat lamaran, daftar riwayat hidup, pas foto terkini, fotocopy KTP, fotocopy ijasah.

Adapun kualifikasi persyaratan umum dan khusus yang harus dilengkapi yaitu sebagai berikut: Persyaratan umum meliputi berpenampilan menarik dan keterampilan bersosial (interpersonal), mempunyai pengalaman kerja di bidang yang sama, kemampuan berbahasa inggris (active), minimal lulusan SMK, diploma tiga atau sarjana, mampu bekerja dalam tekanan, mampu bekerja sebagai bagian dari tim. Adapun persyaratan khusus antara lain beragama Islam, melaksanakan sholat lima waktu, mampu membaca Al-Quran, memahami Islam secara umum. Dalam konteks kualifikasi, hal ini ditegaskan dalam wawancara dengan Human Resource Department. 
"Syariah Hotel Solo merupakan hotel syariah yang mana penerapannya dalam penerapan rekrutmen haruslah berlandaskan dengan Al-Quran dan Hadis di mana sesuai dengan nilainilai syariah yang diterapkan oleh perusahaan. Dan karena itulah Syariah Hotel Solo dalam perekrutan juga ada kualifikasi persyaratan umum dan khusus yang harus dilengkapi" (Sudaryatno \& Yudiantoro, 2021).

Syariah Hotel Solo dalam pengambilan kandidat berasal dari dua sumber untuk mendapatkan calon karyawan sesuai dengan kebutuhan perusahaan yaitu: Pertama, sumber internal yang dilakukan di Syariah Hotel Solo melalui promosi (career path). Career path adalah menaikan jabatan karyawan ke jabatan lain yang memiliki tanggung jawab lebih besar, guna pengembangan pegawai, peningkatan kepuasan kerja, dan peningkatan motivasi kerja di Syariah Hotel Solo. Kedua, sumber eksternal yang dilakukan di Syariah Hotel Solo yang membidik para alumni Sekolah Menengah Kejuruan dan Universitas. Ddalam pengembangannya, Syariah Hotel Solo juga bekerjasama dengan lembaga pendidikan seperti SMK 4, SMK Sahid, IHS, UNS, USS dan lainnya untuk mendapatkan tenaga kerja yang siap guna dan siap pakai, biasanya dimulai dengan penerimaan siswa atau mahasiswa magang. Jika siswa atau mahasiswa itu layak, mereka dapat direkrut menjadi karyawan di Syariah Hotel Solo. Selanjutnya melalui social media, sarana ini merupakan media yang sangat efektif di era digital sekarang dalam komunikasi maupun sebagai penyebar informasi. Syariah Hotel Solo menggunakan social media dalam penyebaran informasi terkait lowongan pekerjaan yang sedang dibutuhkkan.

Dengan demikian, pelaksanaan kebijakan rekrutmen pada penetapan kualifikasi dimaksudkan agar dapat sesuai dengan kebutuhan perusahaan. Hal ini sejalan dengan praktik Islamic Human Resource Management (IHRM) atau HRM Islam yang menekankan pada kompetensi, pengalaman, tanggung jawab, kesesuaian organisasi dan reputasi untuk berkontribusi dalam pencapaian tujuan organisasi (Ali, 2005). Rekrutmen karyawan baru adalah langkah penting dalam praktik HRM Islam. Organisasi harus memastikan bahwa proses rekrutmen dan seleksi diselesaikan dengan pedoman yang telah disusun dan sesuai dengan nilainilai Al-Quran dan Hadis, serta mampu mengemban amanah. Oleh karena itu, bagi perusahaan perlu untuk memilih karyawan yang berkualitas (Hashim, 2009).

Setelah melakukan rekrutmen, langkah berikutnya adalah menyeleksi calon karyawan yang akan bekerja di Syariah Hotel Solo. Adapaun langkah-langkah proses seleksinya antara lain: Pertama, screening lamaran yaitu tahap awal dari proses seleksi yang dilakukan di Syariah Hotel Solo dengan menyaring calon karyawan yang ideal dan sesuai dengan kualifikasi. Kedua, wawancara (interview) yaitu terdapat dua tahap interview di Syariah Hotel Solo, yang pertama adalah interview dengan Human Resource Departement yang bertujuan untuk menggali kepribadian calon karyawan, sedangkan tahap kedua adalah interview dengan Head of Departement dengan pertanyaan-pertanyaan yang bertujuan untuk mengetahui keahlian yang dimiliki calon karyawan. Jika tahap interview calon karyawan lolos maka selanjutnya akan mengikuti tahap berikutnya. Ketiga, pelatihan (training) yaitu pelatihan di Syariah Hotel Solo termasuk tahap seleksi terakhir dalam menilai calon karyawan, tahap ini dilaksanakan selama 3 bulan setelah pelatihan (training) sudah dilaksanakan dengan baik dan calon karyawan mampu 
memenuhi prosedur maka selanjutnya dilakukan perjanjian kontrak (MoU).

Syariah Hotel Solo dalam menjalankan struktur organisasi dan segala pelayanannya berdasarkan manajemen syariah maka adanya tes tambahan dalam proses seleksi yaitu terkait pengetahuan spiritual bagi calon karyawannya yaitu: Pertama, tes membaca Al-Quran, karena Al-Qur'an merupakan pedoman hidup seorang Muslim yang harus di pegang teguh dalam menjalankaan pekerjaan, maka calon karyawan harus mampu membaca atau memahami minimal ayat-ayat pendek yang terdapat dalam Al-Quran. Kedua, tes ibadah di mana calon karyawan haruslah menjalankan ibadah dengan baik, minimal sholat dan bisa mengumandangkan adzan (laki-laki). Hal tersebut bertujuan agar mereka mampu menerapkan nilai- nilai syariah dalam pengaplikasian di setiap aktifitas dalam bekerja, terkhusus ibadah sholat dimana calon karyawan mampu mengerjakan sholat di awal waktu dan tidak meninggalkan sholat maka didalam dirinya tertanam kedisiplinan.

Ketiga, tes pengetahuan agama secara umum yaitu calon karyawan harus memahami mengenai pengetahuan dalam beragama yang mendasar seperti rukun iman, rukun Islam, sejarah Islam, dan berbagai pengetahuan Islam secara umumnya. Karena karyawan di Syariah Hotel Solo bukan hanya menjadi seorang karyawan semata, melainkan harus mampu memberikan value kepada para tamu dan dirinya sendiri dalam hal beragama. Hal ini disampaikan oleh Human Resource Department.

"Sebab Syariah Hotel Solo dalam menjalankan struktur organisasi dan segala pelayanannya berdasarkan manajemen syariah maka adanya tes tambahan dalam proses seleksi yaitu terkait pengetahuan spiritual bagi calon karyawannya" (Sudaryatno \& Yudiantoro, 2021).

Adanya sistem seleksi dengan berpedoman kepada kesesuaian kriteria diharapkan agar terciptanya keadilan di Syariah Hotel Solo sesuai konsep manajemen syariah. Keadilan artinya memberikan jaminan setiap pelamar yang memenuhi persyaratan diberikan kesempatan yang sama dalam seleksi. Selain itu pihak Syariah Hotel Solo dalam menarik calon karyawan hanya akan mengambil calon karyawan yang berkualitas, kompeten, dan benar-benar memenuhi kriteria yang telah ditentukan. Islam menekankan bahwa calon pegawai dipilih berdasarkan prestasi dan kompetensi, tidak dipengaruhi oleh persahabatan, hubungan darah, kekerabatan, usia, kekayaan, ras atau kekuasaan politik (Alorfi, 2012). Seperti yang dinyatakan oleh Human Resource Departmen.

"Tujuan rekrutmen dan seleksi kami untuk mencari yang berkualitas, walaupun ada calon pelamar karena mempunyai hubungan dengan karyawan ataupun hubungan keluarga tetap tidak bisa, namun berbeda lagi kalau kompetensinya bagus bisa dipertimbangkan. Jadi di sini bukan sebagai tempat percobaan. Boleh membawa saudara atau hubungan kerabat asalkan kompetensinya terpenuhi. Karena yang dikhawatirkan akan menimbulkan conflict of interest dan khawatir kompetensinya tidak mumpuni. Jadi untuk menghindari hal-hal seperti itu, kalau tidak ada pengalaman atau kompetensi tetap tidak bisa masuk menjadi pegawai Syariah Hotel Solo (Yudiantoro, 2021).” 
Dalam kajian Mutasim et al. (2013) menunjukkan bahwa kepercayaan karyawan terhadap organisasi sangat relevan dalam praktik Human Resource Management (HRM) Islam, di mana implementasi prinsip keadilan bagi karyawan hal yang utama, sehingga membantu agar tujuan organisasi dapat tercapai. Dengan demikian fungsi sumber daya manusia sangat penting untuk praktik HRM Islam. Prinsipnya adalah kewajiban bagi umat Islam dan lembaga-lembaga Islam untuk menerima dan mentaati aturan-aturan Islam, peraturan dan pedoman sebagai cara hidup untuk menjalankan sebuah organisasi berdasarkan ajaran-ajaran Islam.

\section{Simpulan}

Syariah Hotel Solo, dalam mencari karyawan baru, tidak melakukan rekrutmen karyawan secara berkala, namun akan dilakukan saat terdapat kekosongan pada departemen atau divisi tertentu. Sumber dan metode perekrutan dilakukan melalui internal dan eksternal. Pada sumber internal dilakukan melalui promosi (career path). Sumber eksternal dilakukan melalui sekolah dan universitas yang sudah bekerjasama dengan hotel dan atau social media yang dimiliki Syariah Hotel Solo. Dalam proses seleksi, Syariah Hotel Solo sudah menggunakan waktu yang efektif, baik sesuai dengan perencanaan dan sesuai dengan kualifikasi yang sudah ditentukan baik secara umum maupun khusus. Adapun tahapan- tahapan proses seleksi di Syariah Hotel Solo setelah mengolah informasi berupa: screening lamaran, wawancara, dan pelatihan yaitu berupa evaluasi dalam masa uji coba atau training dilakukan selama tiga bulan untuk melihat kemampuan dan kebiasaan calon karyawan baru. Hal ini dilakukan untuk memantau karakter calon karyawan baru sebelum diangkat menjadi salah satu staf karyawan di Syariah Hotel Solo. Kemudian dalam proses seleksi terdapat tambahan tes khusus yang berkaitan dengan pengetahuan spiritualitas yaitu berupa tes baca Al-Quran, tes ibadah, dan tes pengetahuan agama secara umum. Karyawan yang terpilih berdasarkan kriteria kompetensi dan profesionalitas. Terakhir, dalam proses rekrutmen dan seleksi, Syariah Hotel Solo telah sesuai dengan implementasi konsep manajemen syariah.

\section{Referensi}

Agustin, H. (2018). Sistem Informasi Manajemen Menurut Prespektif Islam. Jurnal Tabarru': Islamic Banking and Finance, 1(1), 63-70. https://doi.org/10.25299/jtb.2018.vol1(1).2045

Ahmat., D. (2013). Syariah Compliant Hotel: the Concept and Practices. Journal of Tourism , Hospitality \& Culinary Arts, 7(2), 52-66.

Ali, A. (2005). Islamic Perspectives on Management and Organization. Edward Elgar Publishing.

Alorfi, S. (2012). Human resource management from an Islamic perspective. Journal of Islamic and Human Advanced Research, 11(2), 86-92.

Basuki, D. (Interviewee). (2021). Food \& Beverage Manager.

Battour, M., Ismail, M.N. and Battor, M. (2011). The impact of destination attributes on Muslim tourist's choice. International Journal of Tourism Research, 13(6), 27.

Fikri, F. (2016). Penerapan Manajemen Sumber Daya Manusia Syariah di Hotel Grasia Semarang. Jurnal Bisnis Strategi, 25(2).

Hafifuddin, D. (2003). Manajemen Syariah Dalam Praktek. Gema Insani. 
Hashim, J. (2009). Islamic revival in human resource management practices among selected Islamic organizations in Malaysia. International Journal of Islamic and Middle Eastern Finance and Management, 2, 251-267. https://doi.org/http://dx.doi.org/10.1108/17538390910986362

Hastutik, R. (2017). Penerapan Manajemen Islam Dalam Suatu Organisasi (Studi Rekrutmen dan Seleksi Karyawan pada CV. Filardhi Surakarta. Institut Agama Islam Negri Surakarta.

Mutasim, N., Ab, N., Alias, M. A., Shahid, S., Hamid, M. A., \& Alam, S. S. (2013). Relationship between Islamic Human Resource Management (IHRM) practices and trust: An empirical study. Journal of Industrial Engineering and Management, 6(4), 1105-1123.

Omar, C. M. C., \& Islam, M. S. (2019). Exploring the Validation of Islamic Hospitality Management in TOurism Destination: Malaysian Perspectives. Journal of Hospitality and Networks, 1, 34-43.

Peraturan Mentri Pariwisata dan Ekonomi Kreatif Republik Indonesia Nomor 2 Tahun 2014 Tentang Pedoman Penyelenggaraan Usaha Hotel Syariah, Pub. L. No. Nomor 2 Tahun 2014 (2014).

Purhantara, W. (2010). Metode Penelitian Kualitatif Untuk Bisnis. Graha Ilmu.

Riasari, A. (2020). Analisis Penerapan Blue Ocean Strategy pada PT Sofyan Hotels, Tbk. AlBuhuts, 16. http://journal.iaingorontalo.ac.id/index.php/ab/article/view/1353

Serhan, O. A. Al, \& Alobaitha, N. A. (2013). Islamic hospitality in the UK: build it and they will come. International Journal of Teaching and Case Studies, 4(2), 171. https://doi.org/10.1504/ijtcs.2013.058804

Solo, S. H. (2021). Buku Pedoman Oprasional Syariah Hotel Solo.

Sucipto. (2020). Konsep Manajemen Sumber Daya Manusia (MSDM) dalam Perspektif Syariah (Telaah Perilaku Bisnis dalam Manajemen Sumber Daya Manusia. Jurnal Studi Islam Dan Mu'amalah, 8(1), 62-79.

Sudaryatno, T. (Interviewer), \& Basuki, D. (Interviewee). (2021). Departement Head Food and Beverage.

Sudaryatno, T. (Interviewer), \& Yudiantoro, W. (Interviewee). (2021). Human Resource Departement.

Sugiyono. (2015). Metode Penelitian Pendidikan (Pendekatan kuantitatif, Kualitatif, dan R\&D) (9798433rd ed.). Alfabeta.

Susanti, M., Abdullah, A., \& Nurjannah. (2019). Analisis Proses Rekrutmen dan Seleksi Calon Karyawan dalam meningkatkan Kinerja Karyawan Pada Hotel Zahra Syariah Kendari. Jurnal BUSINESS UHO: Jurnal Administrasi Bisnis, 4(2), 256-267.

Swa.co.id. (2014). Syariah Hotel Solo: Hotel Syariah Terbesar di Indonesia. https://swa.co.id/swa/trends/marketing/syariah-hotel-solo-hotel-syariah-terbesar-diindonesia

Yusoff, S. Z., Abdullah, N. H., \& Ghazali, M. F. (2017). The functions of advertising in promoting Islamic hospitality. International Journal of Applied Business and Economic Research, 15(15), 537-544.

Zainal, V. R. (2009). Islamic Human Capital Management. PT Raja Grafindo Persada.

Zamani-Farahani, H. and Henderson, J. C. (2010). Islamic tourism and managing tourism development in Islamic societies: the cases of Iran and Saudi Arabia. The International Journal of Tourism Research, 12(1), 79-89. 